\title{
Numerical Modelling of Underground Water Pipelines exposed to Seismic Loading
}

\author{
Dhuha F. Yousife ${ }^{1}$, Asad H. Aldefae ${ }^{1}$, Salah L. Zubaidi ${ }^{1}$, Alaa N. Aldelfee ${ }^{1}$
}

\section{Affiliations}

1Department of Civil Engineering, University of Wasit, Wasit, Iraq

\section{Correspondence}

Dhuha F Yousife,

Department of Civil

Engineering, University of

Wasit, Wasit, Iraq

Email:dhuhaf95@gmail.com

\section{Received}

13-October-2021

Revised

14-November-2021

Re-revised

3-December-2021

Accepted

12- December-2021

Doi: $10.31185 /$ ejuow.Vol9.Iss2.283

\begin{abstract}
The essential factor that must get the interest by the engineers during the primary design stage of underground pipes is understanding mechanism of damage during earthquakes. The attention during design period increased due to the increment of seismic catastrophes throughout the few past decades. Therefore, finite element procedure was used for studying the seismic performance of buried pipes. PLAXIS-2D program was using for simulating the seismic performance of buried pipes using earthquake motion of single frequency. The response of both seismic vertical displacement, and acceleration of the buried pipe were simulated. The experiments of shaking table for two models of buried pipe in dry case that surrounded with sand and gravel were compared with numerical simulation results. According to the obtained results, the amplification of seismic wave raised considerably from the buried pipe base to the pipe crown, the biggest amplification occurred in the highest point of the pipe model. It can be noticed that Plaxis-2D software provides an accurate method for the prediction of seismic behaviour of buried pipe due to the obvious compatibility between the results of experiments and numerical simulation.
\end{abstract}

Keywords: Numerical analysis, buried pipelines, Earthquakes, Seismic displacement, PLAXIS—2D

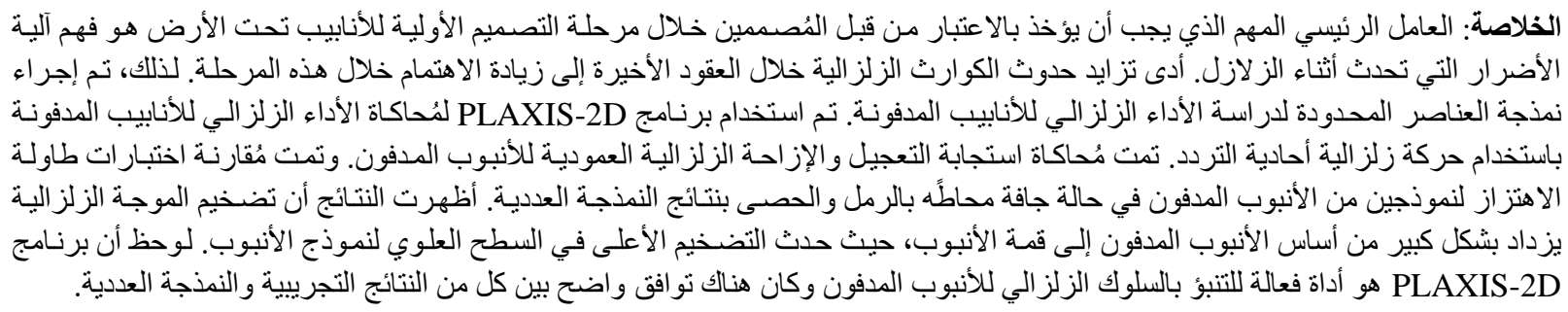

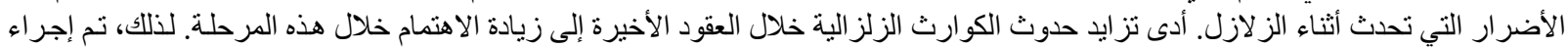

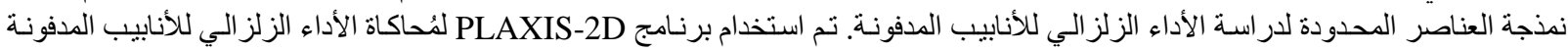

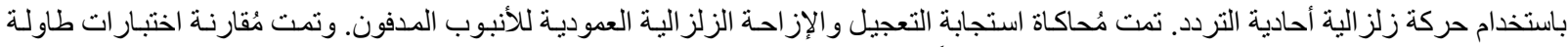

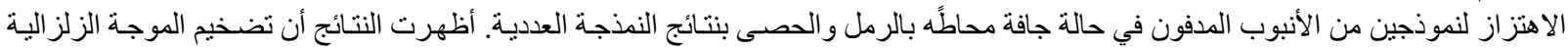

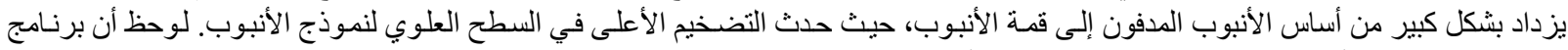

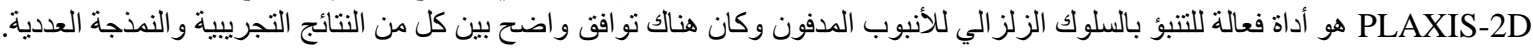

\section{INTRODUCTION}

Buried pipeline systems, which considered an important part of infrastructure lifeline networks, can be used to transport petroleum, gas, or water. The available records of the previous earthquake reveal that earthquake does not cause direct deterioration to systems of pipeline only, but also creates severe secondary damages, including explosion or fire [1]. Accordingly, safety of all lifeline systems is significantly affected by the dynamic response of buried pipe systems. Basically, earthquake produces two kinds of ground movement: temporary and permanent ground deformation. The dynamic ground response represents the transient ground movement, while permanent deformation is considered a quasi-static process and can cause irrecoverable ground movement even after the earthquake stops [2]. Transient ground movement is induced by influence of wave propagation, whereas landslide, fault movement, and liquefication are the possible failures that are categorised as permanent ground deformation. 
Recently, there has been a concerted effort to incorporate the effects of catastrophic natural disasters into risk evaluations. Extreme occurrences such as floods, lightning, hurricanes, and tsunamis are examples of NaTech (Natural events triggering Technological accidents). Many studies, however, have concentrated on the interaction of earthquakes with industrial safety [3] and their consequences on industrial components such as tanks [4], pipelines [5], and wastewater treatment plants [6]. As a result, post-earthquake reconnaissance yielded a large number of examples of damage to industrial components [7]. Furthermore, the seismic reaction is greatly influenced by the soil behaviour during the seismic event, particularly in the case of underground structures [8]. For the risk analysis of the NaTech events stated above, simple tools such as fragility curves and threshold values are required. On the basis of an intensity measure of the natural event, the fragility curves provide the probability of a specific level of damage. The fragilities of seismic effects are commonly described as a function of the peak ground acceleration (PGA) or, less frequently, the peak ground velocity (PGV), as well as other synthetic factors.

Many experts have worked hard over four decades to imagine the reaction of underground flexible pipes subjected to various stress circumstances. Forces of compaction [9], supporting of pipe haunch [10-11], height of backfill [11-15], loads of traffic [10,16-21], erosion voids [22, 23], nearby excavation [24], and soil saturation [25] all had an impact on the behaviour of underground flexible pipes as a result of these intensive efforts. This in-depth knowledge of the behaviour of underground flexible pipes helped engineers in providing better understanding about how the plastic pipes can be broken by various loading conditions, allowing for better designs of these critical lifeline assets. However, several previous studies were directed by the researchers that revealed an abundance of researches about the behaviour of underground flexible pipe carried a transient ground deformation. Previous experiments dealt with the influence of fault displacement only, which means permanent deformation, that induced by earthquake [26-29], there has not any study reported the response of flexible pipe against transient deformation.

The Finite Element Method (FEM) is one of the most reliable studies for underground pipeline seismic response. For many years, researchers have employed FEM to investigate geotechnical difficulties, despite the fact that there are constraints to accurately analyse such problems. However, FEM is favoured to solve linear and nonlinear problems such as predicting of settlement and deformation between buried pipelines and soil [30]. As a result, PLAXIS-2D software is frequently used to evaluate the failure features of subterranean pipelines. Thus, this paper seeks to contribute the literature by examining the parameters that influence the seismic performance of buried unplasticized polyvinyl chloride (UPVC) pipe, which is a flexible pipe, subjected to the seismic load using the finite element method PLAXIS-2D V8.5, and using shaking table test. For example, worthy evidences are presented to suggest that occurrence of crashes in a traffic stream is greatly correlated and increased with a higher variation of vehicle speeds.

\section{NUMERICAL MODELLING}

In the previous years, a significant development can be noticed in the aspect of commercial computer software that is applied for the design and analysis of structures, number of these softwares can be used in the analysis of seismic behaviour of buried pipelines. The analysis process is depended mainly on numerical modelling using two methods: finite difference or finite element analysis. Utilising that commercial compute software, the complicated problems can be solved easily. For example, the seismic performance analysis of underground pipelines, understanding the mechanism of fluid-structure-soil interaction, determining vertical seismic displacement of the buried pipe model, and determining parameters required for dynamic loads [31]. The method of finite element can be considered the most common method that certainly provides a comprehensive procedure to analyse the behaviour of soil structure subjected to seismic loading, it has some advantages in considering the natural failure mechanisms and the interaction of structure-soil system. Despite the fact that several commercial computer programs may be applied for seismic design of buried pipe model, these programs still have several demerits in determining the major design parameters. One of the most popular programs for analysing buried pipe is (PLAXIS 2D, V8.5), where the experimental outcomes of the current study will be verified by finite element analysis depending on this program. In this program, the dynamic model is limited to plane stain and axisymmetric cases. A nonlinear time history analysis has been carried out using a model analysis of PLAXIS-2D plain strain. 


\subsection{Constitutive model}

As shown in Figure 1, the buried pipe model was drawn with minimizing scale of 1/30 for the actual prototype. It is modelled and analysed utilising PLAXIS-2D software version 8.5, which is a finite element program. the nonlinearity of geometry (interface), and material (in soil) was taken in consideration in this study. The modelling of the model of buried pipe and soil was performed depending on 15 nodded plain strain triangular elements [32].

The prescribed displacement was assumed in the horizontal direction to restrain the motion in vertical direction, while the area of contact between the soil and buried pipe model was modelled using a model with special interface elements. The units used to define the model were the unit of time, which was in seconds because the dynamic effect is normalised in the order of second instead of day, and the units of dimensions were in meters. Standard fixity, which was utilised for simulating the model in actual and absorbent boundaries, was applied as a special state have to be applied to absorb waves that reach the external boundaries of the model. For models of plain strain, the absorbent boundaries were created at right-hand, left-hand and the bottom boundaries [33].

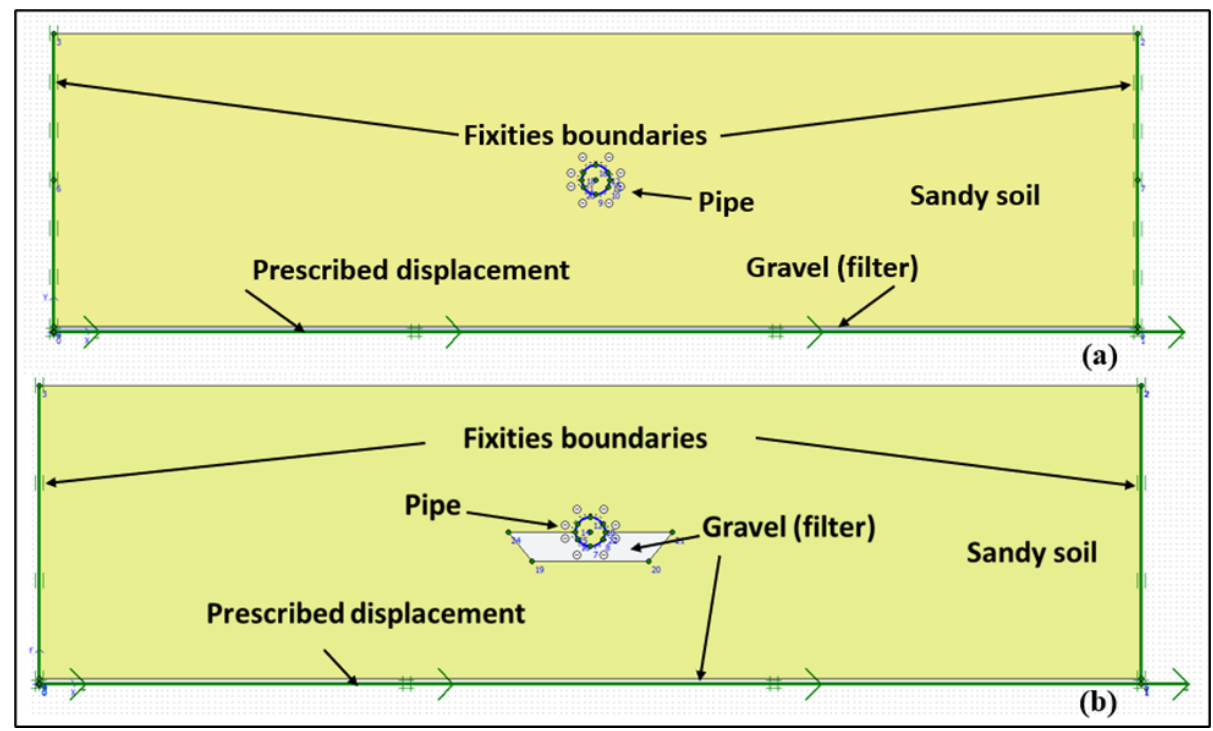

Figure 1 Typical mesh configuration of pipe model; (a) test 1 (b) test 2.

\subsection{Properties of model material}

For forecasting the behaviour of buried pipe model, a suitable soil model and appropriate design characteristics must be considered as the input parameters. The soil was the most complicated material and different kinds of material models can be subjected to solve geotechnical problems by analytical and numerical analysis. The available models of soil in PLAXIS-2D (V8.5) program are linear elastic model, hardening soil model, soft soil model, soft soil creep model, the articulated rock model, and Hardening soil small model. Dynamic analysis was performed in PLAXIS-2D using hardening soil model with small strain stiffness (HS small) [32,34]. This model was selected because it is the most reliable model available in PLAXIS-2D for seismic or cyclic loading calculations in order to obtain reasonable outcomes, whereas other models were only expected to give crude approximations [34]. The properties of materials were displayed in Table 1. The layers of sand soil and gravel (filter) were modelled as a hardened soil model with small stiffness (HS small), while the UPVC pipe used in FEM was selected as a tunnel element composed of plate material buried in sand and modelled as a linear elastic model. The pipe's modulus of elasticity was considered equal to $689 \mathrm{MPa}$ [32].

Table 1 Engineering parameters for sandy soil and gravel (filter) [35].

\begin{tabular}{|c|c|c|c|c|c|}
\hline Symbol & Parameters & Units & Sand & Gravel (filter) & Pipe \\
\hline$\gamma_{\text {unsat }}$ & Unsaturated unit wight & $\mathbf{k N} / \mathrm{m}^{3}$ & 18 & 16 & - \\
\hline$\gamma_{\text {sat }}$ & Saturated unit weight & $\mathbf{k N} / \mathrm{m}^{3}$ & 18 & 16 & - \\
\hline $\mathbf{E}_{\mathbf{5 0} \text { ref }}$ & $\begin{array}{c}\text { Reference secant } \\
\text { young's models }\end{array}$ & $\mathbf{k N} / \mathrm{m}^{2}$ & $\mathbf{5 0 0 0 0 0}$ & $\mathbf{2 0 0 0 0}$ & - \\
\hline $\mathbf{E}_{\text {oed ref }}$ & Reference dilatancy angle & $\mathbf{k N} / \mathrm{m}^{2}$ & $\mathbf{5 0 0 0 0}$ & $\mathbf{2 0 0 0 0}$ & - \\
\hline $\mathbf{E}_{\text {ur ref }}$ & $\begin{array}{c}\text { Reference unloading-reloading } \\
\text { modulus }\end{array}$ & $\mathbf{k N} / \mathrm{m}^{2}$ & $\mathbf{1 5 0 0 0 0}$ & $\mathbf{6 0 0 0 0}$ & - \\
\hline $\mathbf{P}_{\text {ref }}$ & Reference stress & $\mathbf{k N} / \mathrm{m}^{2}$ & $\mathbf{1 0 0}$ & 100 & - \\
\hline
\end{tabular}




\begin{tabular}{|c|c|c|c|c|c|}
\hline $\mathbf{K}_{\mathbf{0} \mathbf{n c}}$ & Earth pressure coefficient at rest & - & $\mathbf{0 . 4 7 0}$ & $\mathbf{0 . 3 5 7}$ & - \\
\hline $\mathbf{V}_{\mathrm{ur}}$ & Possion ratio & - & $\mathbf{0 . 2 0}$ & $\mathbf{0 . 2 0}$ & - \\
\hline $\mathbf{R}_{\mathbf{f}}$ & Failure ratio & - & $\mathbf{0 . 9 0}$ & $\mathbf{0 . 9 0}$ & $\mathbf{0 . 9 0}$ \\
\hline$\Psi$ & Dilatancy angle & Degree & 4 & 10 & - \\
\hline Power & $\begin{array}{c}\text { Power for stress level } \\
\text { dependency }\end{array}$ & - & $\mathbf{0 . 5}$ & $\mathbf{0 . 5}$ & $\mathbf{0 . 5}$ \\
\hline $\boldsymbol{\emptyset}_{(\mathbf{p h i})}$ & Shear stress angle & Degree & 34 & 40 & - \\
\hline
\end{tabular}

\subsection{Mesh generation}

In the dynamic analysis, mesh plays main role in finding logical result if not for simple geometry, but certainly for complex one. The generation of mesh in PLAXIS is completely automatic and depended on strong triangulation method that results irregular mesh. For automatic mesh in PLAXIS one can use 6-node or 15-node elements. In the current study, 15-node triangular elements were considered for two cases [32] to provide higher accuracy and enhanc the ability to pick up stress concentration. The dimensions of these models were $(1.88 * 0.51)$ and the radius of pipe was $0.025 \mathrm{~m}$. Figure 2 displays the mesh generation for the two cases.

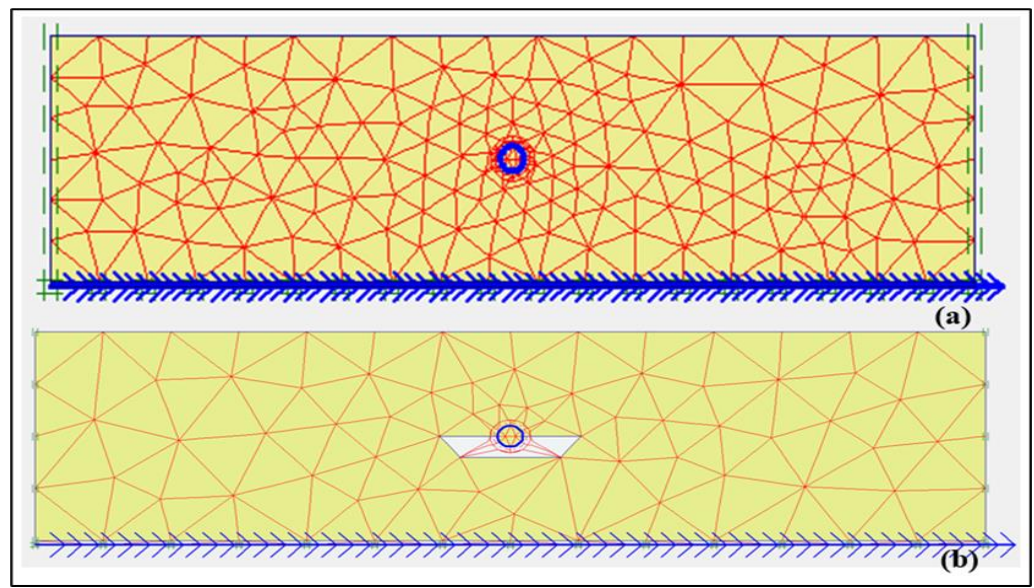

Figure 1 Typical mesh configuration of pipe model; (a) test 1 (b) test 2.

\subsection{Input motion}

The used input motion in numerical modelling in this program was similar to the input motion depended in the experimental work using shaking table, so the validation between numerical modelling and experimental work results was more logical. The input motion used in the modelling is displayed in Figure 3.

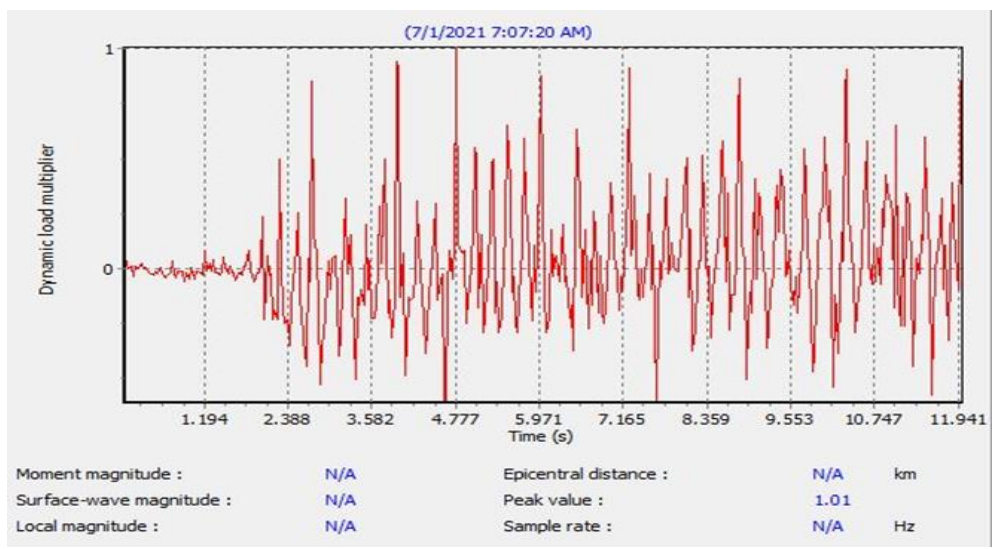

Figure 2 Input motion used in this modelling.

\section{METHODOLOGY}

As shown in Figure 4, three points (A, B and C) were chosen for evaluating the acceleration response in these points and vertical displacement in point $\mathrm{C}$ as those points represent the sites of sensors in the laboratory shaking table tests (sites of LVDT and accelerometers) to compare the outcomes of the experimental tests which achieved 
in laboratory using 1 -g shaking table test and relative density of sand soil was $55 \%$ and the numerical simulation by FEM.

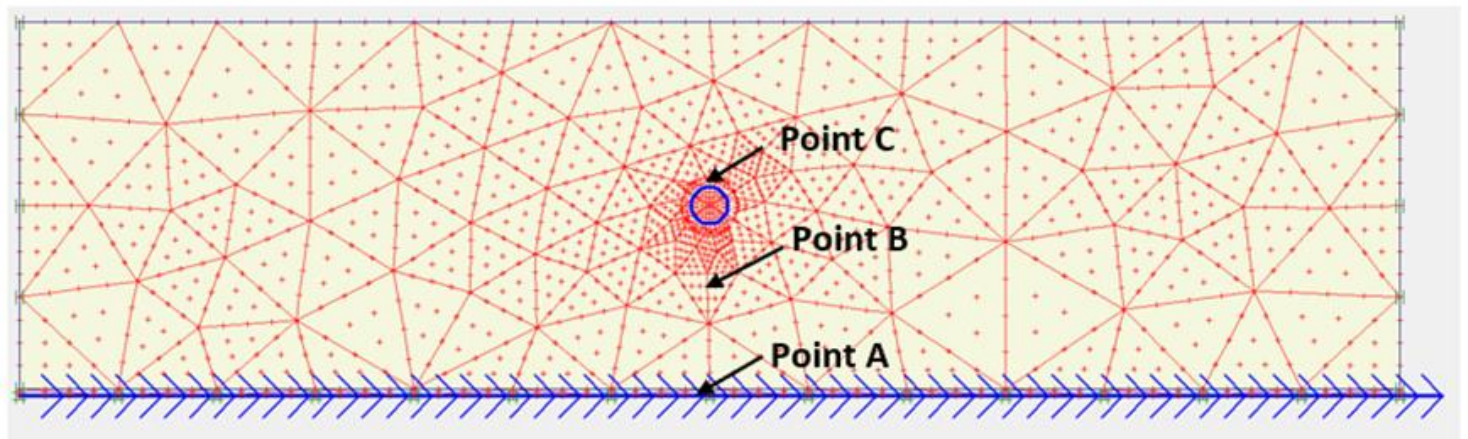

Figure 3 The location of acceleration and displacement measurement point.

\section{RESULTS}

\subsection{Results of comparison between numerical and experimental modelling (T-1)}

In this section, the results of displacement and acceleration obtained by 1-g shaking table tests (the results of experimental work) are compared with those obtained by PLAXID-2D V8.5 software. The outcomes of comparison are shown in Figures (5 and 6). The shaking table tests outcomes were applied as verification tools.

\subsubsection{Comparison between measured and predicted acceleration}

Figure 5 displays the measured and predicted acceleration at various positions. It is obvious from the figure, the harmony between the predicted and the experimental data can be considered reasonably acceptable due to the weakness of the 2-dimensional predictions including the assumption of rigid side boundaries. For the experimental box, the walls were not fully rigid, this may influence the predictions of finite element analysis. The time history of acceleration correspondence with the output of finite elements analysis was satisfactory. It was noticed that the measured acceleration showed an agreement with the predicted acceleration Acc.1 (i.e., input motion), Acc. 2 and Acc.3.

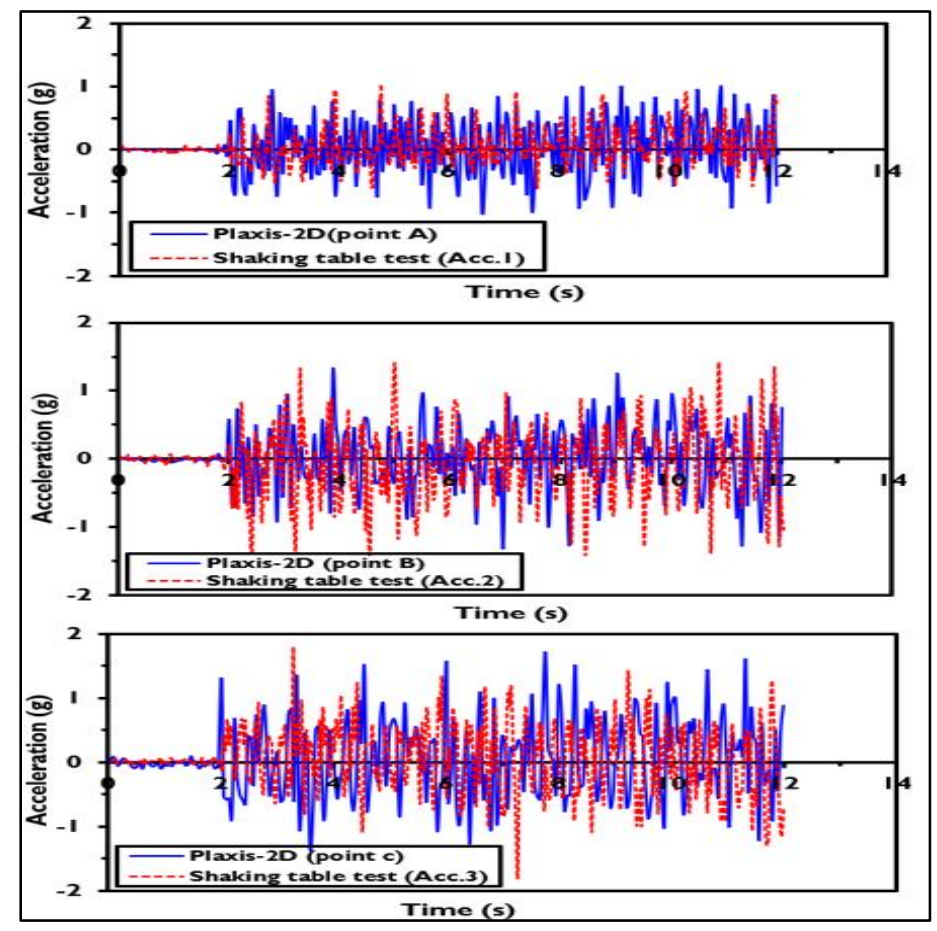

Figure 5 Comparison of predicted and measured acceleration (T-1). 


\subsubsection{Comparison between predicted and measured vertical displacement}

Figure 6 displays the comparison between the measured and predicted vertical displacement (settlement). The response of the pipe to the vertical displacement obtained from this study showed a good agreement with the response obtained from the shaking table tests. However, the maximum deviation between the numerical modelling results and the recorded data of shaking table test was from 5 to $8 \mathrm{sec}$. From 8 to $12 \mathrm{sec}$, the results of the numerical modelling began to correspond with the results of shaking table test.

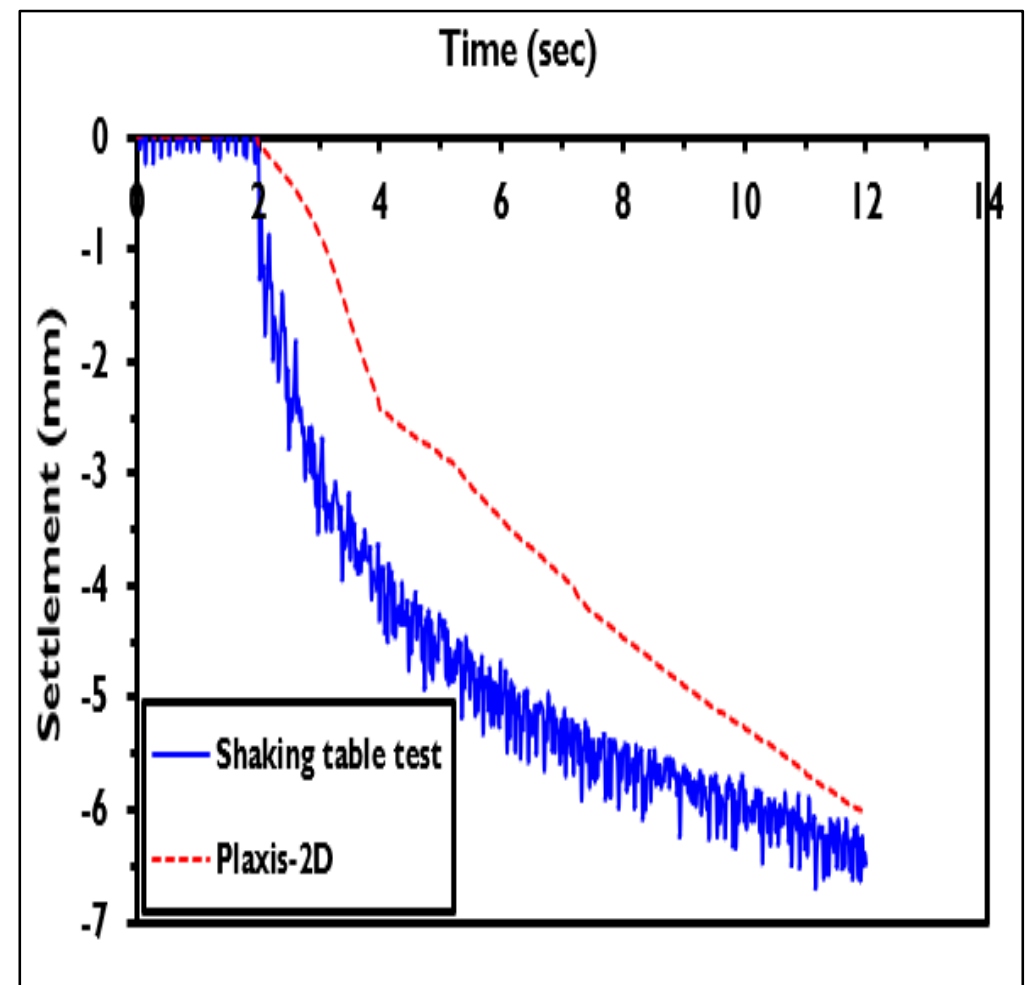

Figure 6 Comparison between measured and predicted settlement (T-1).

\subsection{Results of Comparison between Numerical and Experimental Modelling (T-2)}

\subsubsection{Comparison between Predicted and Measured Acceleration}

Experimental and numerical studies showed that the propagation of seismic waves are from the base of the shaking table to the middle layer of foundation, while attenuation occurred at the pipe crown due to presence of gravel layer that dissipates the seismic waves and this principle is consistent with experimental work as shown in Figure 7. However, similarities in the general tendency of acceleration encourage such an application (numerical analysis) to simulate and reasonably estimate the acceleration response during vibration of buried underground pipes. It should be noticed also that the numerical simulation showed acceptable verification for the time acceleration recorded in Acc. 2, which is underneath the pipe. This is very important outcomes as the seismic behaviour of the pipe is strongly influenced by the shaking of the soil at this position. 

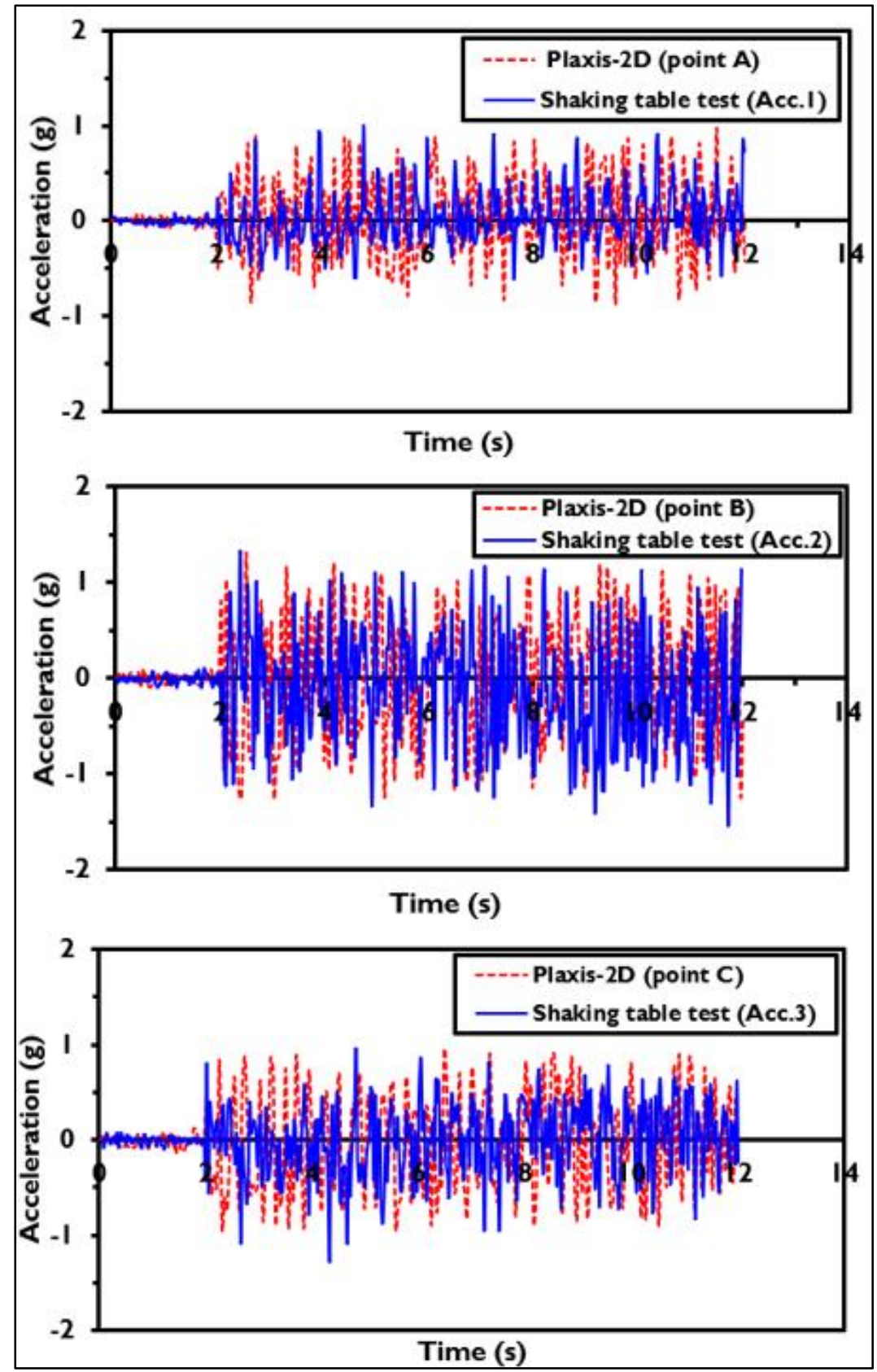

Figure 7 Comparison between predicted and measured acceleration (T-2.

\subsubsection{Comparison between predicted and measured vertical displacement}

The results of settlement response obtained from the current numerical study using PLAXIS-2D was closer to the experimental results of the shaking table tests that obtained by the PLAXI-2D as shown in Figure 8. Also, the results showed that the settlement of the pipe influenced with the material under pipe (i.e., the gravel that contributed to reduce the vertical displacement). The settlement of pipe (in PLAXIS-2D) began at 3 sec, while the settlement of pipe began at $2 \mathrm{sec}$ using shaking table test. The results of PLAXIS-2D`displayed increase about $3.5 \%$ from that of shaking table. 


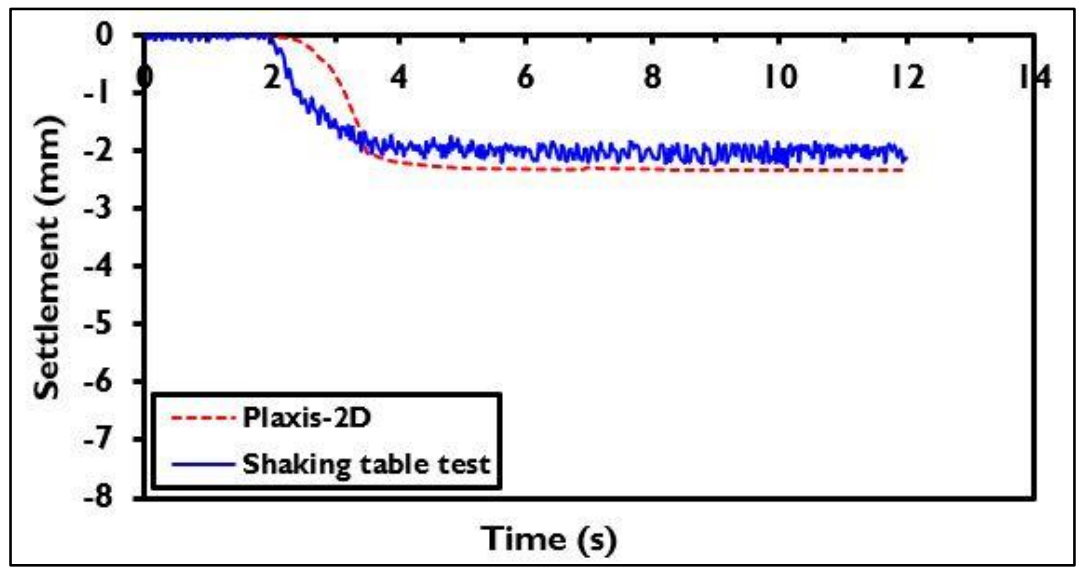

Figure 8 Comparison between measured and predicted settlement (T-2).

\subsection{Comparison of amplification between between two cases}

Figure (9.a) displays the amplification factor for (T-1), it increased with the depth and this increasing in PLAXIS-2D was compatible with the experimental work. Therefore, the amplification factor for (T-2) showed the increasing occurred at depth of $0.12 \mathrm{~m}$ but decreased at depth of $0.31 \mathrm{~m}$.
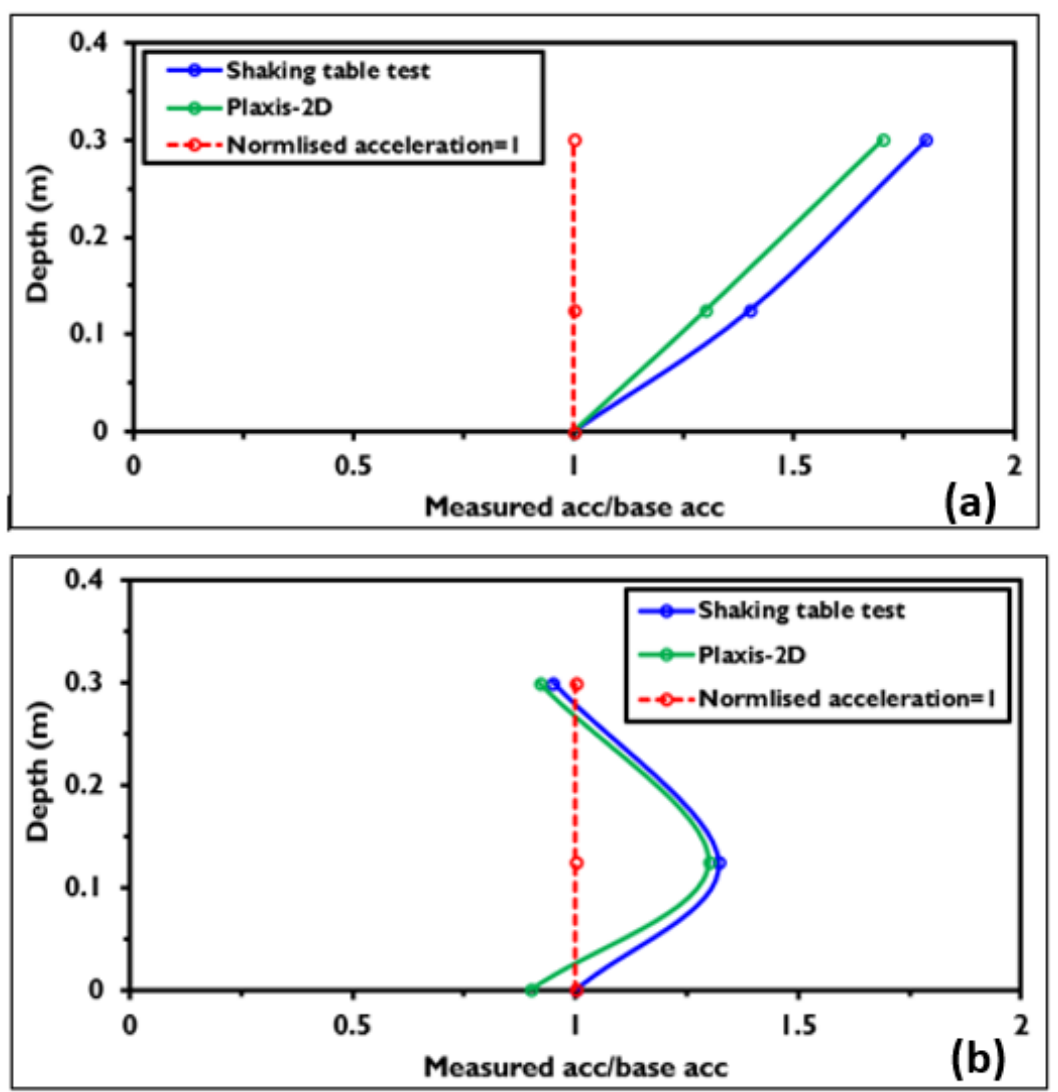

Figure 9 Comparison between normalised acceleration with depth for numerical and experimental modelling (a) for T-1, (b) for T-2.

It can be seen also for the Figure 9,b that the gravel layer surrounded the pipe and prevented hysterical strain during shaking, thus the normalised measured and predicted acceleraton is less than unity.

\section{CONCLUSIONS}

The current study focused on utilising technique of numerical modelling (utilising PLAXIS-2D program) to study the dynamic response of underground pipe in two cases. This was performed by simulating the buried pipe in 
reality and the seismic outcomes were compared with that obtained from shaking table tests in laboratory. The main conclusions are summarised below:

1. The displacement and acceleration response of the literature study (i.e. shaking table tests) were well captured.

2. The outcomes displayed that the amplification of seismic acceleration enhanced considerably at the top of buried pipe model when the sandy soil was used as a backfill soil but there is attenuation at the pipe crown when the gravel placed up to the height of pipe springline, as a result the gravel dissptates the energy of seismic waves

3. Depending on the histories of time-acceleration that are achieved from any seismic station near the site, the model of finite element can be applied for primary design during the dynamic response estimation for the suggested structure.

4. The predicted dynamic vertical displacement for the first case showed the maximum deviation between the numerical modelling results and the recorded data of shaking table test was from 5 to $8 \mathrm{sec}$. After that the results of the numerical modelling began to correspond with the results of shaking table test.

5. The settlement of pipe for the second case (in PLAXIS-2D) began at $3 \mathrm{sec}$, while the settlement of pipe began at $2 \mathrm{sec}$ using shaking table test. The results of PLAXIS-2D displayed increase about $3.5 \%$ from that of shaking table.

6. According to the achieved outcomes for the time-acceleration and the displacement from the numerical modelling utilising PLAXIS-2D, one can notice that the numerical approach is an acceptable method for predicting the seismic behaviour of the underground pipe model.

\section{REFERENCES}

1. Wang, D. (2010). Response of underground pipeline to random ground motion. Tianjin, China: Tianjin Univ. Tianjin.

2. O'rourke, T. D., \& Jeon, S. S. (2000, November). Seismic zonation for lifelines and utilities. In Invited Keynote Paper on Lifelines. Proceedings sixth international conference on seismic zonation, Palm Springs, EERI CD ROM.

3. Campedel, M., Cozzani, V., Garcia-Agreda, A., \& Salzano, E. (2008). Extending the quantitative assessment of industrial risks to earthquake effects. Risk Analysis: $A n$ International Journal, 28(5), 1231-1246.

4. Salzano, E., Iervolino, I., \& Fabbrocino, G. (2003). Seismic risk of atmospheric storage tanks in the framework of quantitative risk analysis. Journal of Loss Prevention in the Process Industries, 16(5), 403-409.

5. Lanzano, G., Salzano, E., de Magistris, F. S., \& Fabbrocino, G. (2013). Seismic vulnerability of natural gas pipelines. Reliability Engineering \& System Safety, 117, 7380

6. Lanzano, G., de Magistris, F. S., Fabbrocino, G., \& Salzano, E. (2014). Integrated approach to the seismic vulnerability assessment of industrial underground equipment and pipelines. Bollettino di Geofisica Teorica ed Applicata, 55(1).

7. Panico, A., Lanzanoa, G., \& Salzanoc, E. (2013). Seismic vulnerability of wastewater treatment plants. Chemical Engineering, 32.

8. Lanzano, G., de Magistris, F. S., Fabbrocino, G., \& Salzano, E. (2014). Integrated approach to the seismic vulnerability assessment of industrial underground equipment and pipelines. Bollettino di Geofisica Teorica ed Applicata, 55 (1).

9. Elshimi, T. M., \& Moore, I. D. (2013). Modeling the effects of backfilling and soil compaction beside shallow buried pipes. Journal of Pipeline Systems Engineering and Practice, 4(4), 04013004 
10.Alzabeebee, S., Chapman, D. N., \& Faramarzi, A. (2018). Innovative approach to determine the minimum wall thickness of flexible buried pipes. Geomechanics Eng., 15(2), 755-767.

11.Dhar, A. S., Moore, I. D., \& McGrath, T. J. (2004). Two-dimensional analyses of thermoplastic culvert deformations and strains. Journal of geotechnical and geoenvironmental engineering, 130(2), 199-208.

12.Kang, J., Parker, F., \& Yoo, C. H. (2007). Soil-structure interaction and imperfect trench installations for deeply buried corrugated polyvinyl chloride pipes. Transportation research record, 2028(1), 192-202.

13.Kang, J. S., Stuart, S. J., \& Davidson, J. S. (2013). Analytical evaluation of maximum cover limits for thermoplastic pipes used in highway construction. Structure and Infrastructure Engineering, 9(7), 667-674

14.Sargand, S., Masada, T., Tarawneh, B., \& Gruver, D. (2008). Deeply buried thermoplastic pipe field performance over five years. Journal of geotechnical and geoenvironmental engineering, 134(8), 1181-1191.

15.Zhou, M., Du, Y. J., Wang, F., Arulrajah, A., \& Horpibulsuk, S. (2017). Earth pressures on the trenched HDPE pipes in fine-grained soils during construction phase: Full-scale field trial and finite element modeling. Transportation Geotechnics, 12, 56-69.

16. Alzabeebee, S., Chapman, D. N., \& Faramarzi, A. (2018). A comparative study of the response of buried pipes under static and moving loads. Transportation Geotechnics, 15, 39-46.

17.Chaallal, O., Arockiasamy, M., \& Godat, A. (2015). Field test performance of buried flexible pipes under live truck loads. Journal of Performance of Constructed Facilities, 29(5), 04014124.

18.Chaallal, O., Arockiasamy, M., \& Godat, A. (2015). Numerical finite-element investigation of the parameters influencing the behavior of flexible pipes for culverts and storm sewers under truck load. Journal of Pipeline Systems Engineering and Practice, 6(2), 04014015

19.Fattah, M. Y., Hassan, W. H., \& Rasheed, S. E. (2018). Behavior of flexible buried pipes under geocell reinforced subbase subjected to repeated loading. International Journal of Geotechnical Earthquake Engineering (IJGEE), 9 (1), 22-41.

20.Fattah, M. Y., Hassan, W. H., \& Rasheed, S. E. (2018). Effect of geocell reinforcement above buried pipes on surface settlement. International Review of Civil Engineering, 9(2), 86-90.

21.Kang, J., Stuart, S. J., \& Davidson, J. S. (2014). Analytical study of minimum cover required for thermoplastic pipes used in highway construction. Structure and Infrastructure Engineering, 10(3), 316-327.

22.Balkaya, M., Moore, I. D., \& Sağlamer, A. (2012). Study of non-uniform bedding due to voids under jointed PVC water distribution pipes. Geotextiles and Geomembranes, 34, 39-50.

23.Balkaya, M., Moore, I. D., \& Sağlamer, A. (2013). Study of non-uniform bedding support under continuous PVC water distribution pipes. Tunnelling and underground space technology, 35, 99-108.

24.Al-Khazaali, M., Vanapalli, S. K., \& Oh, W. T. (2019). Numerical investigation of soilpipeline system behavior nearby unsupported excavation in saturated and unsaturated glacial till. Canadian Geotechnical Journal, 56(1), 69-88.

25.Alzabeebee, S. (2020). Influence of backfill soil saturation on the structural response of buried pipes. Transportation Infrastructure Geotechnology, 7(2), 156-174.

26.Sim, W. W., Towhata, I., \& Yamada, S. (2012). One-g shaking-table experiments on buried pipelines crossing a strike-slip fault. Geotechnique, 62(12), 1067-1079. 
27.Sim WW, Towhata I, Yamada S, Moinet GM (2012) Shaking table tests modelling small diameter pipes crossing a vertical fault. Soil Dyn Earthq Eng 35:59-71.

28.Xie, X., Symans, M. D., O'Rourke, M. J., Abdoun, T. H., O'Rourke, T. D., Palmer, M. C., \& Stewart, H. E. (2011). Numerical modeling of buried HDPE pipelines subjected to strike-slip faulting. J.Earthq Eng, 15(8): 1273-1296.

29. Xie X, Symans MD, O'Rourke MJ, Abdoun TH, O'Rourke TD,

Palmer MC, Stewart HE (2013) Numerical modeling of buried HDPE pipelines subjected to normal faulting: a case study. Earthq Spectra 29(2):609-632

30. Cameron, D. A. (2005). Analysis of buried flexible pipes in granular backfill subjected to construction traffic.

31. Malaki, S., \& Mahjoubi, S. (2010). A new approach for estimating the seismic soil pressure on retaining walls.

32. Alzabeebee, S. (2019). Response of buried uPVC pipes subjected to earthquake shake. Innovative Infrastructure Solutions, 4(1), 1-14. ISO 690.

33. Brinkgreve, R. B. J., \& Borer, W. (2006). Plaxis Dynamics Manual (v 8.5). Delft University of Technology and Plaxis bv, Netherlands

34. Özhan, H. O., Bayat, E. E., \& Zanjani, E. Y (2016, September). Dynamic Analysis of Buried Pipelines with Geogrid Reinforcement.

35. Aldelfee, A. N., Aldefae, A. H., \& Zubaidi, S. L. (2021). Numerical modelling of seismic performance of gravity quay wall. Materials Science and Engineering, 1058, 18. 